\title{
Article \\ Vitamin C and E Treatment Blocks Changes in Kynurenine Metabolism Triggered by Three Weeks of Sprint Interval Training in Recreationally Active Elderly Humans
}

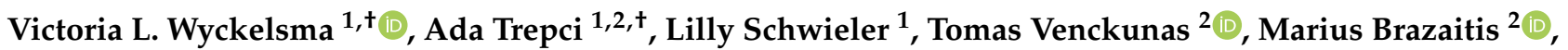 \\ Sigitas Kamandulis ${ }^{2}$, Henrikas Paulauskas ${ }^{2}$, Helena Gapeyeva ${ }^{3,4}{ }^{\oplus}$, Mati Pääsuke ${ }^{4}\left(\mathbb{D}\right.$, Stefano Gastaldello ${ }^{1}(\mathbb{D}$, \\ Sophie Imbeault ${ }^{1}$, Håkan Westerblad ${ }^{1,2}{ }^{\circ}$, Sophie Erhardt ${ }^{1}$ and Daniel C. Andersson ${ }^{1,5, *}$
}

check for updates

Citation: Wyckelsma, V.L.; Trepci, A.; Schwieler, L.; Venckunas, T.; Brazaitis, M.; Kamandulis, S.; Paulauskas, H.; Gapeyeva, H.; Pääsuke, M.; Gastaldello, S.; et al. Vitamin C and E Treatment Blocks Changes in Kynurenine Metabolism Triggered by Three Weeks of Sprint Interval Training in Recreationally Active Elderly Humans. Antioxidants 2021, 10, 1443. https://doi.org/10.3390/ antiox10091443

Academic Editor:

Christine Feillet-Coudray

Received: 6 July 2021

Accepted: 8 September 2021

Published: 10 September 2021

Publisher's Note: MDPI stays neutral with regard to jurisdictional claims in published maps and institutional affiliations.

Copyright: (c) 2021 by the authors Licensee MDPI, Basel, Switzerland. This article is an open access article distributed under the terms and conditions of the Creative Commons Attribution (CC BY) license (https:/ / creativecommons.org/licenses/by/ $4.0 /)$.
1 Department of Physiology and Pharmacology, Karolinska Institutet, 17177 Stockholm, Sweden; victoria.wyckelsma@ki.se (V.L.W.); ada.trepci@ki.se (A.T.); lilly.schwieler@ki.se (L.S.); stefano.gastaldello@ki.se (S.G.); sophie.imbeault@ki.se (S.I.); hakan.westerblad@ki.se (H.W.); sophie.erhardt@ki.se (S.E.)

2 Institute of Sports Science and Innovations, Lithuanian Sports University, 44221 Kaunas, Lithuania; tomas.venckunas@lsu.lt (T.V.); marius.brazaitis@lsu.lt (M.B.); sigitas.kamandulis@lsu.lt (S.K.); henrikas.paulauskas@lsu.lt (H.P.)

3 Clinic of Medical Rehabilitation, Inpatient Rehabilitation Centre, East Tallinn Central Hospital, 10138 Tallinn, Estonia; helena.gapeyeva@ut.ee

4 Institute of Sport Sciences and Physiotherapy, Faculty of Medicine, University of Tartu, 50090 Tartu, Estonia; mati.paasuke@ut.ee

5 Cardiology Unit, Karolinska University Hospital, 17164 Stockholm, Sweden

* Correspondence: daniel.c.andersson@ki.se

+ Equal contribution.

Abstract: The kynurenine pathway $(\mathrm{KP})$ is gaining attention in several clinical fields. Recent studies show that physical exercise offers a therapeutic way to improve ratios of neurotoxic to neuroprotective KP metabolites. Antioxidant supplementation can blunt beneficial responses to physical exercise. We here studied the effects of endurance training in the form of sprint interval training (SIT; three sessions of 4-6 $\times 30$ s cycling sprints per week for three weeks) in elderly ( 65 years) men exposed to either placebo $(n=9)$ or the antioxidants vitamin C ( $1 \mathrm{~g} /$ day $)$ and $\mathrm{E}(235 \mathrm{mg} /$ day $)(n=11)$. Blood samples and muscle biopsies were taken under resting conditions in association with the first (untrained state) and last (trained state) SIT sessions. In the placebo group, the blood plasma level of the neurotoxic quinolinic acid was lower $(\sim 30 \%)$ and the neuroprotective kynurenic acid to quinolinic acid ratio was higher $(\sim 50 \%)$ in the trained than in the untrained state. Moreover, muscle biopsies showed a training-induced increase in kynurenine aminotransferase (KAT) III in the placebo group. All these training effects were absent in the vitamin-treated group. In conclusion, KP metabolism was shifted towards neuroprotection after three weeks of SIT in elderly men and this shift was blocked by antioxidant treatment.

Keywords: skeletal muscle; mitochondria; antioxidants; reactive oxygen/nitrogen species; endurance training; sprint interval training

\section{Introduction}

Biological ageing involves a progressive decline of cellular function, is a high-risk factor for morbidity, and places individuals at higher risk of diseases [1,2]. Within an increasingly ageing population, actions towards health promotion are critical not only to improve the quality of life for older individuals but also to mitigate escalating health care costs. The kynurenine pathway (KP) is a unique pathway implicated in a high number of pathologies associated with ageing, including those affecting bone, skeletal muscle, cardiovascular, and mental health [3-5]. Moreover, changes in KP metabolites both in the 
cerebrospinal fluid and in serum have been shown to relate to age in healthy individuals as well as in patients with age-related disorders [6-10]. Furthermore, a correlation between changes in KP metabolites and frailty status has been recently shown in older humans [11].

In short, the KP pathway begins with the breakdown of free tryptophan where about $95 \%$ of free tryptophan is turned into kynurenine by the enzymes indoleamine 2,3-dioxygenase 1 (IDO1) and tryptophan 2,3-dioxygenase 2 (TDO2). Kynurenine can be metabolized into either the neuroprotective kynurenic acid by kynurenine aminotransferases (KATs) [12] or the free radical generator 3-hydroxykynurenine by kynurenine 3-monooxygenase. 3-hydroxykynurenine is then eventually turned into the neurotoxic quinolinic acid or the protective picolinic acid [13,14]. Importantly, kynurenine and its metabolites-including quinolinic acid and 3-hydroxykynurenine-are strongly correlated to depression, schizophrenia, and other neurodegenerative disorders [15-17]. Quinolinic acid in particular is linked with many disorders acting as a neurotoxin, proinflammatory mediator, pro-oxidant molecule, and by affecting the integrity and cohesion of the blood-brain barrier [18].

Chronic low-grade inflammation and a redox imbalance with excessive production of reactive oxygen/nitrogen species (ROS) relative to the antioxidant defense are considered major factors underlying age-related functional impairments [1,19], including impaired skeletal muscle function [1,19], and the generation of quinolinic acid and 3-hydroxykynurenine have been linked to inflammation and oxidative stress [20]. Physical exercise is known to have a positive influence on ageing by reducing chronic low-grade inflammation and negative ROS-induced effects [21]. Intriguingly, the production of ROS is increased during health promoting endurance exercise $[22,23]$ and antioxidant treatment has been shown to reduce beneficial effects of endurance training [24-27], although other studies report no blunting of exercise-induced adaptations by antioxidant treatment $[28,29]$.

Endurance exercise stimulates mitochondrial biogenesis, including increased expression of mitochondria-targeted KATs that promote the conversion of kynurenine to kynurenic acid [30]. Young adults who engaged in endurance training displayed increased KAT IV and enhanced conversion of kynurenine to kynurenic acid when compared to resistance-type exercise [31,32]. Basal kynurenine metabolites in plasma from older adults have been investigated in a 12-week training study where both resistance exercise (two days per week) and high-intensity exercise $(10 \times 60$ s efforts at $\sim 90 \%$ max HR, one day per week) were undertaken [33]. The study did not detect large changes, nonetheless positive trends for decreases in kynurenine and increases in more neuroprotective metabolites were observed [33]. Another study found no improvement in depressed patients levels of kynurenine, kynurenic acid, or their ratios following 12 weeks of low-to-moderate training [34]. However, in that study the KP metabolites were not measured in immediate conjunction to the exercise effort but up to a week after the final training session [34].

Sprint interval training (SIT) is an endurance exercise modality that is short in duration, yet highly metabolically demanding, which has the potential to induce exercise adaptations in a time efficient way. Here, we studied whether KP metabolism was altered in older adults exposed to three weeks of repeated SIT sessions. Given the important role of skeletal muscle kynurenine conversion [30], and that highly trained endurance athletes have more KATs in their muscles than recreationally active people [32], we also assessed if KATs were upregulated following the three weeks of repeated SIT sessions. Finally, due to proposed opposing effects of ROS in ageing (i.e., functional deterioration due to chronic low-grade oxidative stress vs. beneficial effects of transitory ROS increases during physical training sessions), we studied the effects of treatment with the antioxidants vitamin $C$ and $E$ on KP-related responses to SIT. We hypothesize that three weeks of SIT will have positive effects on the balance between neuroprotective and neurotoxic KP metabolites and that it will increase the expression of KATs in muscle, and that these effects will be blunted by the antioxidant treatment. 


\section{Materials and Methods}

\subsection{Volunteers and Training}

The volunteers in this study and training protocols have been described before [26]. Briefly, recreationally active male older adults $(65.3 \pm 1.5$ years; $n=20)$ participated in the study; none of the participants were engaged in any structured sport training program but undertook approximately of $4-5 \mathrm{~h}$ of exercise a week upon enrolment into the study. The participants were instructed to continue their normal diet and sleeping habits during the study, but these aspects were not strictly controlled or followed up.

Subjects performed three weeks of SIT while being treated with high doses of antioxidants in the form of vitamin C ( 1 g daily) and vitamin E ( $235 \mathrm{mg}$ daily; $n=11)$ or placebo $(n=9)$. We used the same doses of vitamins as in previous studies addressing the effects of antioxidants on the response to training $[24,25,27]$; it should be noted that these doses are about an order of magnitude higher than recommended daily intakes. Treatments were initiated 7 days before the first SIT session to ensure that there was a stable increase vitamin $\mathrm{C}$ and $\mathrm{E}$ levels prior to exercise interventions. At the time of the study, none of the subjects was diagnosed with a neurological disorder or mental illness. Training adherence was $100 \%$ with no adverse events being reported. The study was approved by the Kaunas Regional Biomedical Research Ethics Committee (ethics number BE-2-35) and was in agreement with the Declaration of Helsinki. All participants gave written informed consent before participation.

Training consisted of nine sessions (three sessions a week for three weeks). Each session consisted of a warm-up followed by 4-6 repetitions of $30 \mathrm{~s}$ all-out cycling bouts (Wingate tests) with $4 \mathrm{~min}$ of rest between bouts [26,35]. A cycle ergometer with continuous power recording was used to quantify the amount of work produced during each SIT session. Vastus lateralis muscle biopsies were taken before the first (untrained state) and before the last (trained state) SIT sessions. Antecubital venous blood samples were collected before and $24 \mathrm{~h}$ after the first (untrained state) and the last (trained state) SIT sessions (Figure 1). Note that muscle biopsies and blood samples were taken under resting conditions, i.e., at least $24 \mathrm{~h}$ after a SIT session. All testing before and after the SIT were conducted at the same time of day and volunteers were required to maintain their regular diet including replicating diet in the $24 \mathrm{~h}$ prior to each testing session.

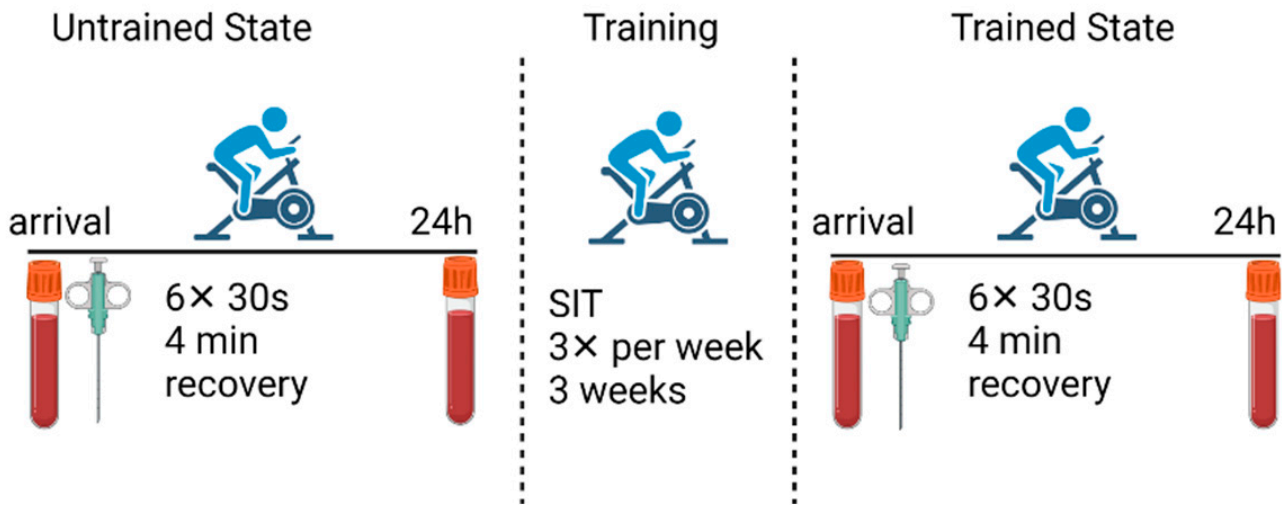

Figure 1. Schematic overview of the study outline. Volunteers undertook the first sprint interval training (SIT) session (untrained state) followed by three weeks of SIT training. The final training session (trained state) identical measures were taken. Tubes and needle indicate taking blood samples and muscle biopsies, respectively. 


\subsection{Plasma Preparation}

Plasma samples were collected in vacuum tubes using EDTA as an anticoagulant (EDTAK3, $3 \mathrm{~mL}$ ), mixed gently by inverting $8-10$ times, and kept at $2-8{ }^{\circ} \mathrm{C}$ until centrifugation. Blood samples were centrifuged at $1200 \times \mathrm{g}$ for $15 \mathrm{~min}$ within $30 \mathrm{~min}$ after blood collection. Plasma was separated from the red blood cells as soon as possible (maximum, $10-15 \mathrm{~min}$ ) after centrifugation and kept at $-80^{\circ} \mathrm{C}$ until analysis. $30 \mu \mathrm{L}$ of plasma sample was mixed with $30 \mu \mathrm{L}$ of internal standard $0.5 \mu \mathrm{M}$ in $10 \%$ ammonium hydroxide (UPLC grade) solution and vortexed for $15 \mathrm{~s} .60 \mu \mathrm{L}$ of $200 \mathrm{nM} \mathrm{ZnSO}_{4}\left(+5^{\circ} \mathrm{C}\right)$ was added and vortexed for $15 \mathrm{~s} .30 \mu \mathrm{L}$ of methanol $\left(+5^{\circ} \mathrm{C}\right)$ (UPLC grade) was added and vortexed for $15 \mathrm{~s}$. The mixture was centrifuged for $10 \mathrm{~min}$ at $2841 \times g$ at room temperature. $30 \mu \mathrm{L}$ of the supernatant was mixed with $30 \mu \mathrm{L}$ of formic acid 5\% in LC-MS Certified Clear Glass $12 \times 32 \mathrm{~mm}$ vials (Waters, Manchester, UK, product no. 186005662CV). Vials were transferred to an autosampler (set to $5^{\circ} \mathrm{C}$ ) that injected $1.5 \mu \mathrm{L}$ into the ultra-performance liquid chromatography tandem mass spectrometry (UPLC-MS/MS) system [36].

\subsection{Ultra-Performance Liquid Chromatography/Mass Spectrometry (UPLC-MS/MS)}

Tryptophan, kynurenine, kynurenic acid, quinolinic acid, 3-hydroxykynurenine, and picolinic acid in plasma were analyzed simultaneously using UPLC-MS/MS system using a Xevo TQ-XS triple-quadrupole mass spectrometer (Waters, Manchester, UK) equipped with a Z-spray electrospray interface and a Waters Acquity UPLC I-Class FTN system (Waters, MA, USA). The MS was operated in electrospray-positive multiple reaction monitoring (MRM) mode. The conditions were set as follows: interface: electrospray; source temperature of $150{ }^{\circ} \mathrm{C}$; desolvation gas flow rate $1000 \mathrm{~L} / \mathrm{h}$; cone gas flow rate: $150 \mathrm{~L} / \mathrm{h}$; capillary voltage of $3.0 \mathrm{kV}$; desolvation temperature $650^{\circ} \mathrm{C}$; and detector gain 1 . The column used was Acquity HSS T3 $1.8 \mu \mathrm{m}$ with dimensions $2.1 \times 150 \mathrm{~mm}$, (Waters, Manchester, UK, serial number: 186003540 ) and set to a temperature of $50^{\circ} \mathrm{C}$. In addition, a guard column (Waters, Manchester, UK, Vanguard HSS T3 $1.8 \mu \mathrm{m} 2.1 \times 50$ mm column, PN: 186003976) was installed to retain contaminants from the mobile phase. The two used mobile phases consisted in: solvent A: $0.6 \%$ formic acid in water (UPLC grade) and solvent B: $0.6 \%$ formic acid in methanol (UPLC grade). The flow rate used was $0.3 \mathrm{~mL} / \mathrm{min}$ and the run time for each sample was $13.0 \mathrm{~min}$. For more detailed and method validation see [36].

$\mathrm{KP}$ metabolites show large variations between individuals at rest and over time in connection with exercise [36,37]; individual data of KP metabolites in association with the first SIT session in the placebo group have been published [36]. Here we focused on KP metabolite levels under resting conditions and to get robust values, we use the mean of measurements preformed in each individual before and $24 \mathrm{~h}$ after SIT sessions in the untrained and trained state, respectively. In a few cases, successful measurements were not obtained both before and $24 \mathrm{~h}$ after exercise and only one value was then used.

\subsection{Muscle Biopsies}

We used previously described and validated procedures for taking needle muscle biopsies [38]. Briefly, after skin sterilization and local anesthesia, a 1-2 mm-long skin cut was made with the tip of a scalpel. Biopsies were collected from vastus lateralis muscles using an automatic biopsy device (Pajunk DeltaCut, Geisingen, Germany). A 14-gauge disposable needle was inserted through the cut, perpendicular to the muscle fibers, until the fascia was pierced. Two to three samples ( 15 mg each) were collected from one puncture site at each time point. A local compression was then applied on the biopsy site for a few min. Muscle samples were immediately frozen in liquid nitrogen and stored at $-80{ }^{\circ} \mathrm{C}$.

\subsection{Western Blotting}

Approximately $10 \mathrm{mg}$ of frozen muscle was weighed and homogenized on ice (1:20 w/v) in HEPES lysis buffer (20 mM HEPES, $150 \mathrm{mM} \mathrm{NaC1}, 5 \mathrm{mM}$ EDTA, $25 \mathrm{mM} \mathrm{KF}$, 5\% Glycerol, $1 \mathrm{mM} \mathrm{Na}_{3} \mathrm{VO}_{4}, 0.5 \%$ Triton, $\mathrm{pH}$ 7.6) with Protease Inhibitor (no. 11836145001, Roche, 1 tablet per $50 \mathrm{~mL}$ ). Homogenate was diluted to $33 \mu \mathrm{g}$ wet weight muscle per $\mu \mathrm{L}$ using 
$3 \times$ SDS denaturing solution ( 0.125 M Tris-HCI, 10\% glycerol, 4\% SDS, $4 \mathrm{M}$ urea, $10 \%$ 2-mercaptoethanol and $0.001 \%$ Bromophenol Blue, $\mathrm{pH}$ 6.8). Finally, samples were further diluted to $2.5 \mu \mathrm{g}$ wet weight muscle per $\mu \mathrm{L}$ with $1 \times$ SDS solution $(3 \times$ SDS denaturing solution diluted 2:1 with $1 \times$ Tris. $\mathrm{Cl}(\mathrm{pH}$ 6.8)). A calibration curve with muscle samples from healthy young adults (18-35 years) was run on every gel for western blotting. All samples were stored at $-80^{\circ} \mathrm{C}$ until analysis.

$10 \mu \mathrm{g}$ of protein was separated on either 18 or 26 well $4-15 \%$ TGX stain-free gels, after separation gels had total protein visualized prior to transfer and analysis on Image Lab software (Image Lab 6.0, Bio-Rad, Hercules, CA, USA). Protein was wet transferred to polyvinylidene fluoride (PVDF) membrane followed by blocking at room temperature for $2 \mathrm{~h}$ using LI-COR Intercept buffer in phosphate-buffered saline (PBS). After blocking, membranes were incubated in primary antibody overnight at $4{ }^{\circ} \mathrm{C}$ and for $2 \mathrm{~h}$ at room temperature. Primary antibody details are as follows: KAT I (anti-CCBL1, 121156-1AP, Proteintech, 1:1000), KAT III (anti-CCBL2, HPA026538, Atlas Antibodies, Stockholm, Sweden. 1:200), KAT IV (GOT2. ARP43518_T100, Aviva systems biology, 1:1000), and TDO2 (15880-1-AP, Proteintech, 1:1000). All antibodies were diluted in LI-COR Intercept buffer in PBS, 1:1 $v / v$ with $1 \times$ tris-buffered saline with Tween (TBST). After incubation in primary antibody, membranes were washed in $1 \times$ TBST, incubated in secondary antibody (1:20,000, IRDye 680-conjugated donkey anti-mouse IgG and IRDye 800-conjugated donkey anti-rabbit IgG (926-68,072; 926-32,213; LI-COR Biosciences) and immunoreactive bands were visualized using infrared fluorescence on an IR-Odyssey scanner. Band densities were analyzed using Image Studio Lite v 5.2 (LI-COR Biosciences, Lincoln, NE, USA). During data analysis, the density of each given protein was measured relative to the calibration curve and then normalized to the total protein as measured for each lane in stain-free gels. The same calibration curve was used across all gels and data are expressed relative to the average of the pre training biopsies from each group on each gel.

\subsection{Statistical Analysis}

Data are presented as mean \pm SEM. Statistical analyses were performed with GraphPad Prism 8 (Graphpad Software Inc., San Diego, CA, USA) Statistically significant differences were analyzed by a two-way repeated measures analysis of variance (ANOVA), which was followed by Tukey's post-hoc test when an effect of training and/or treatment (placebo vs. vitamin) was observed. Significance was set at $p<0.05$.

\section{Results}

\subsection{KP Metabolites in Plasma at Rest in the Untrained and Trained States}

To assess whether three weeks of SIT alters plasma KP metabolites in the rested state and if this was affected by vitamin $C$ and $E$ supplementation, we measured six KP metabolites in connection with the first (untrained state) and the final (trained state) SIT sessions. The results show a statistically significant reduction of the neurotoxic quinolinic acid in the trained state in the placebo group, whereas this KP metabolite was not affected by training in the vitamin-treated group (Figure 2).

The plasma kynurenine to tryptophan (KYN/TRP) ratio has been used to assess the activity in the initial step of the KP [39]. We observed no differences in the KYN/TRP ratio either between the untrained and trained states or between placebo and vitamin-treated subjects (Figure 3A). Another commonly used measure is the ratio between the neuroprotective kynurenic acid and the neurotoxic quinolinic acid (KYNA/QUIN) [32,40-42]. In the placebo group, the KYNA/QUIN ratio was $\sim 50 \%$ higher in the trained than in the untrained state, whereas it was not affected in the vitamin-treated group (Figure 3B). Thus, three weeks of SIT appeared to induce KP-related neuroprotection in the placebo group but not in the vitamin-treated group. 

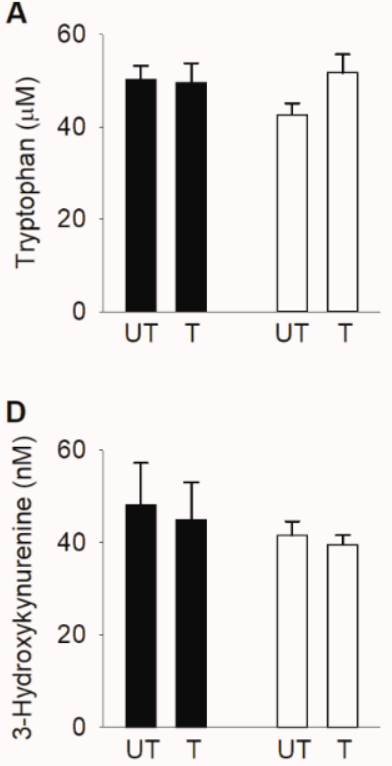

B
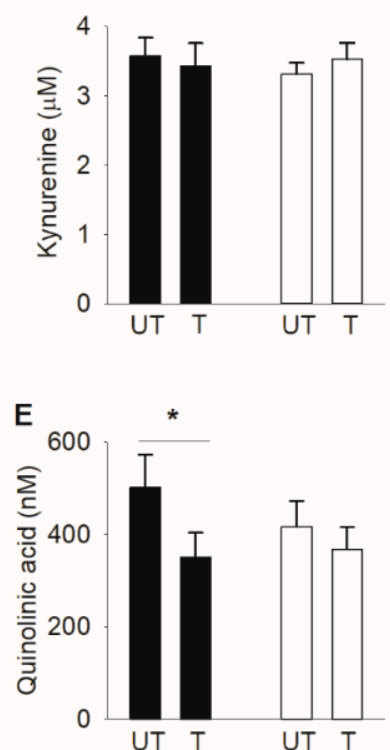

C
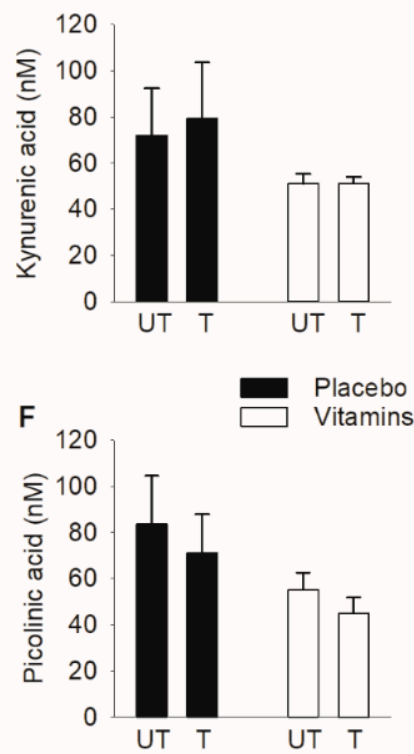

Figure 2. Effects of three weeks of SIT with or without antioxidant supplementation on KP metabolites in plasma of resting individuals. (A) Tryptophan, (B) kynurenine, (C) kynurenic acid, (D) 3-hydroxykynurenine, (E) quinolinic acid, and (F) picolinic acid in plasma in connection with the first (untrained, UT) and the last (trained, T) SIT sessions. Black bars, placebo group $(n=9)$ and white bars, vitamin-treated group $(n=11)$. Data presented as mean \pm SEM. ${ }^{*} p<0.05$ between untrained and trained state with two-way repeated measures ANOVA followed by Tukey's post-hoc test.

A

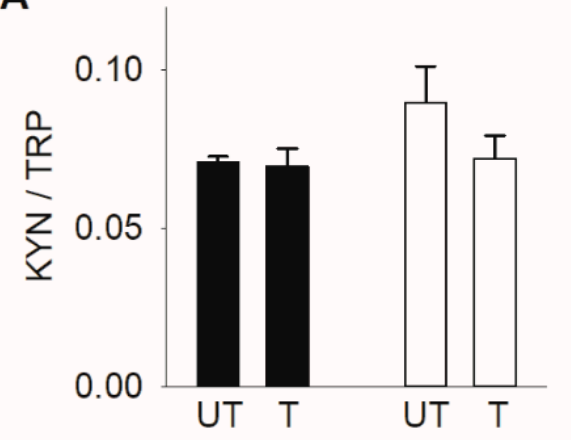

B

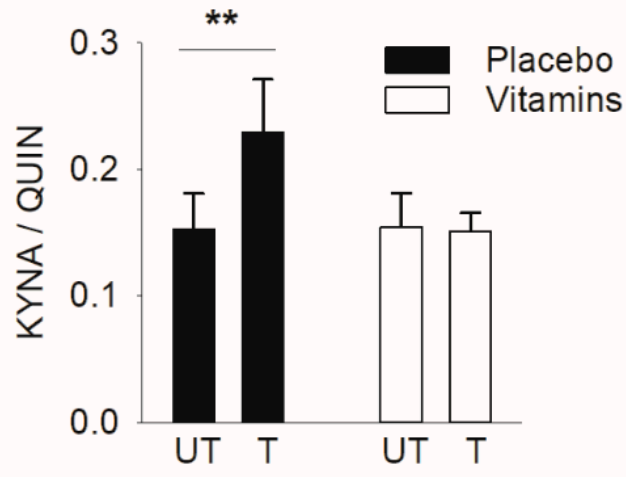

Figure 3. Three weeks of SIT increased the kynurenine acid to quinolinic acid ratio only in the placebo group. (A) The kynurenine to tryptophan (KYN/TRP) and (B) kynurenine acid to quinolinic acid (KYNA/QUIN) ratios in plasma in connection to the first (untrained) and last (trained) SIT sessions. Black bars, placebo group $(n=9)$; white bars, vitamin-treated group $(n=11)$. Data presented as mean \pm SEM. ${ }^{* *} p<0.01$ between untrained and trained state with two-way repeated measures ANOVA followed by Tukey's post-hoc test.

\subsection{KAT Protein Expression in Muscle following Three Weeks of SIT}

We previously showed that KAT I-IV expression is higher in muscle of trained endurance cyclists compared to recreationally active individuals [32], hence indicating a positive effect of endurance training on KAT expression. However, in the present study, investigating older subjects, we only observed a higher expression KAT III in the trained than in the untrained state in the vitamin-treated group, whereas all other KAT measurements showed no difference between the two states (Figure 4). Moreover, the protein expression of muscle TDO2, which facilitates the conversion of tryptophan to KYN, was not changed following training in either group. 
A
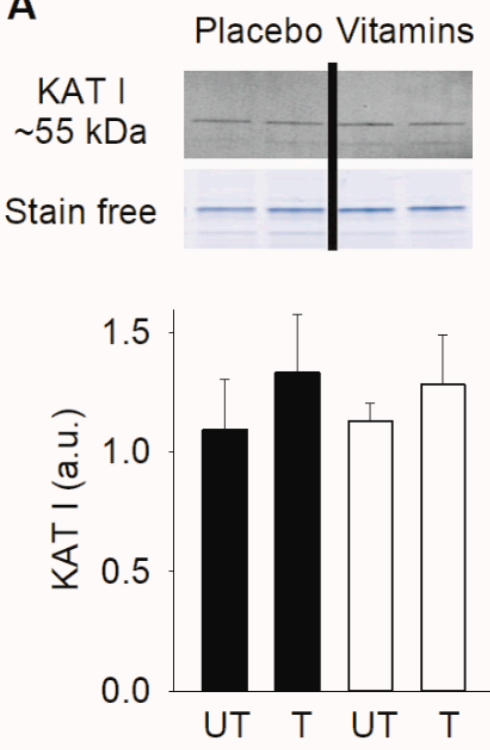

C
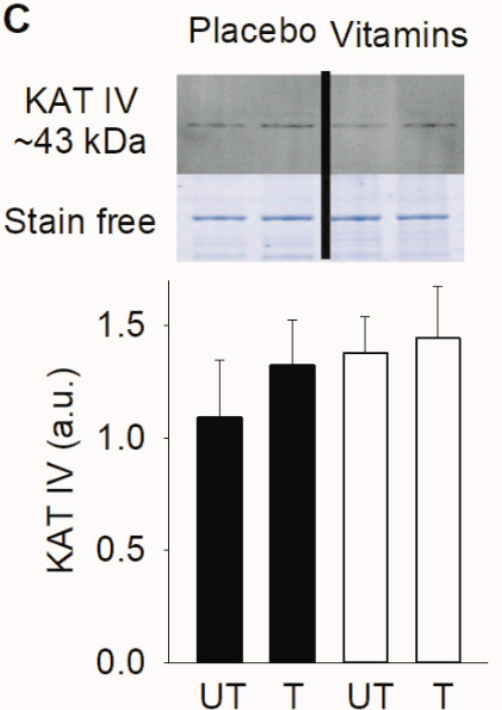

B
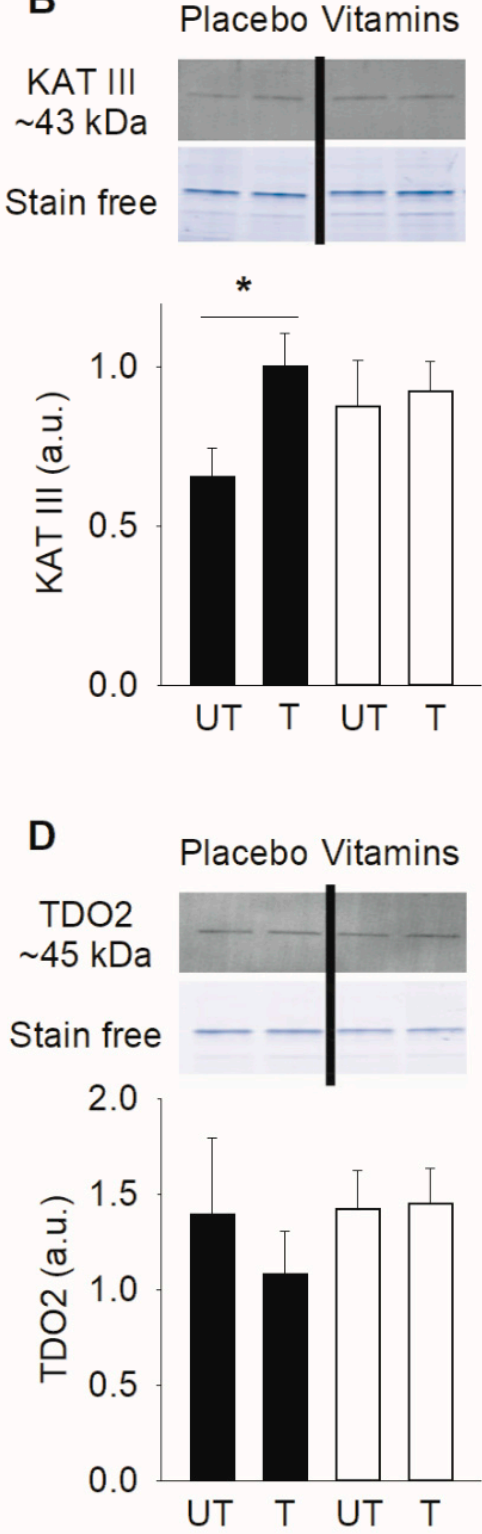

Figure 4. Three weeks of SIT increased KAT III protein expression in the placebo but not in the vitamin-treated group. Mean data ( \pm SEM) and representative blots for (A) KAT I, (B) KAT III, (C) KAT IV, and (D) TDO2 in skeletal muscle biopsies taken under resting conditions in the untrained (UT) and trained (T) states. Black bars, placebo group $(n=7-8)$; white bars, vitamin-treated group $(n=8-9)$. Stain free images were used as total protein loading controls and the actin band in such stain free images reflected the total protein content and are shown below the Western blots. Each protein was normalized against its own calibration curve $(\sim 5-40 \mu \mathrm{g}$ wet weight protein) and expressed relative total protein loading. ${ }^{*} p<0.05$ between untrained and trained state with two-way repeated measures ANOVA followed by Tukey's post-hoc test.

\section{Discussion}

We here tested the hypothesis that three weeks of endurance training in the form of repeated SIT sessions would have a positive effect on KP metabolism in elderly men and that this effect would be blunted by antioxidant treatment with vitamin $C$ and $E$. In accordance with our hypothesis, the results show decreased blood plasma concentration of the neurotoxic quinolinic acid and an increased muscle protein expression of KAT III in the placebo group but not in the vitamin-treated group. 
Chronic inflammatory mechanisms elevate several KP intermediates, including quinolinic acid, as shown by elevated quinolinic acid levels found in cerebrospinal fluid and post-mortem brain tissue of patients with neuroinflammatory disorders [43]. Furthermore, increased quinolinic acid is linked to anxiety in animal models [44] and a reduction in the kynurenic acid/quinolinic acid ratio is commonly observed in depressed patients [40-42]. Intense physical exercise can induce acute muscle inflammation. However, a well-described benefit of regular physical exercise is its systemic anti-inflammatory effects, which are not exclusive to skeletal muscle [45]. In the present study, we measured plasma KP metabolites under resting conditions before (untrained state) and at the end (trained state) of the three weeks of repeated SIT sessions, which promote ROS-dependent inflammatory signaling [26]. Our results show that in the placebo group, the quinolinic acid plasma concentration was decreased by $\sim 30 \%$ and the kynurenic acid/quinolinic acid ratio was $\sim 50 \%$ higher in the trained state. Thus, these results imply that the three weeks of SIT triggered mental health-promoting changes KP metabolism. In this context, it is intriguing that the effect was obtained with a total of only 7-9 min of high-intensity exercise per week. Furthermore, the effect seems robust in that it was statistically significant with the limited number of individuals included in the study and without full control of diet and sleep, factors that can affect the concentration of KP metabolites [46,47].

In contrast to the placebo group, we observed no potentially beneficial training effect on KP metabolism in the vitamin-treated group, which fits with previous studies showing that antioxidant supplementation can hinder benefits of physical exercise [24-27,48]. Thus, the results of our study adds effects on KP metabolism to the general concept of previous studies describing intricate effects of ROS, where transient and over-time-limited ROS challenges can be beneficial whereas prolonged ROS increases are likely to be detrimental $[49,50]$.

The conversion of kynurenine to kynurenic acid is catalyzed by four KATs. Here, we measured the protein expression of three of these (KAT I, III, and IV), of which KAT III and IV are targeted to the mitochondria $[4,12,30]$. We previously showed that, despite a generally higher mRNA expression of genes encoding mitochondria-related proteins in the placebo than in the vitamin-treated group after three weeks of SIT, the expression of mitochondrial electron complex proteins only displayed a non-significant tendency towards being higher in the placebo group and the maximal oxygen uptake during cycling remained unchanged [26]. Nevertheless, we here show an approximate $50 \%$ increase in KAT III protein expression in trained placebo-exposed subjects, whereas the three weeks of SIT had no effect on KAT III protein expression in the vitamin-treated group. This result broadly fits with the observed changes in KP metabolites (decreased quinolinic acid levels and increased kynurenic acid to quinolinic acid ratio), where an increased KAT activity would shift the KP balance to kynurenine being converted to kynurenic acid rather than being further metabolized to quinolinic acid. The lack of effect of SIT on the protein expression of KAT III in the vitamin-treated group provides yet another example of a training response that is hampered by antioxidant treatment [25-27].

We observed no effect of the three weeks of SIT on the protein expression of TDO2, which is one of the enzymes that catalyzes the conversion of tryptophan to kynurenine, in either the placebo or vitamin-treated groups. In accordance with this result, we did not observe any training-induced effects on the plasma levels of tryptophan or kynurenine or the ratio between these two KP metabolites.

High-intensity interval training has proven to be an effective and time-efficient training regimen for healthy individuals, as well as for individuals suffering from diseases that limit exercise performance [51]. Recent meta-analyses show improved aerobic exercise performance in young sedentary or recreationally active individuals after a period of highintensity interval training similar to that used in the present study [52-54]. However, the SIT regimen used in the present study did not improve the aerobic capacity of the elderly participants [26] and the present effects on KP metabolism were relatively small. It has previously been show that nine SIT sessions effectively increases the aerobic capacity of elderly individuals [55]. In that study, the nine SIT sessions were performed over six weeks 
compared to three weeks in the present study. Thus, larger effects on KP metabolism than those reported here might be expected with a longer total training period than three weeks and/or with longer rest periods between training sessions [26].

\section{Conclusions}

The KP metabolism was shifted in a neuroprotective direction after three weeks of SIT, with a total of less than $30 \mathrm{~min}$ of high-intensity exercise, in recreationally active elderly men and this shift was blocked by antioxidant treatment with vitamin $\mathrm{C}$ and $\mathrm{E}$ (Figure 5). Thus, transient ROS increases during SIT sessions emerge as important triggers of beneficial adaptations and this signaling is disturbed by antioxidant treatment. Still, the effect was relatively modest and future studies where individuals perform SIT over a longer time frame and/or with longer rest periods between SIT sessions are required to establish whether this type of training effectively promotes beneficial changes in KP metabolism in an elderly population.

\section{3 weeks of sprint interval training}

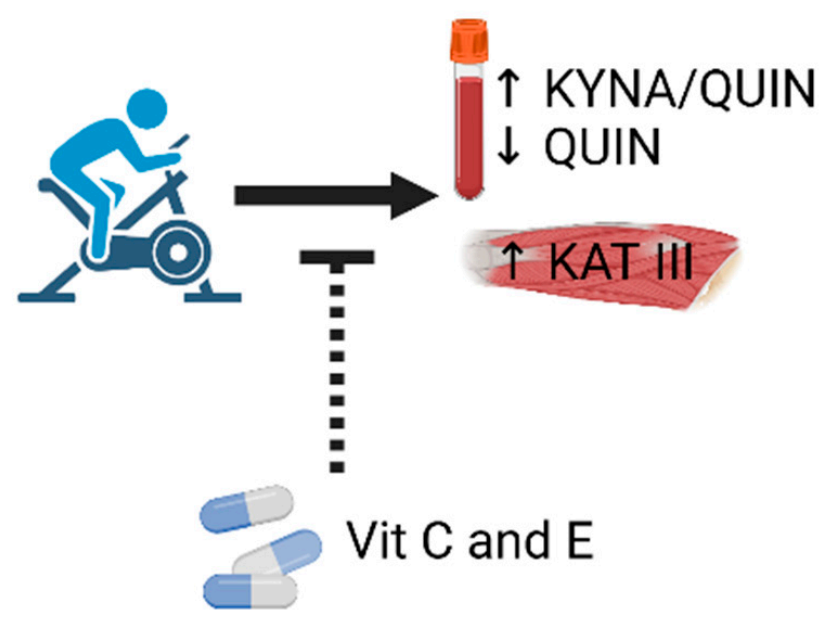

Figure 5. Graphical summary of major results. Three weeks of SIT altered important aspects of kynurenine metabolism: decreased quinolinic acid levels and increased kynurenic acid to quinolinic acid ratio in plasma and increased KAT III expression in skeletal muscle. Per oral administration of the antioxidant vitamins $C$ and $E$, prior to and during the exercise period, blocked these potentially neuroprotective training effects.

Author Contributions: Conceptualization, V.L.W., T.V., S.K., H.W., S.E. and D.C.A.; Methodology and performing experiments, V.L.W., A.T., L.S., T.V., M.B., H.P., H.G., M.P., S.G. and S.I.; Data analysis, V.L.W., A.T., L.S., S.G., S.I., H.W. and S.E.; Writing-original draft preparation, V.L.W. and A.T.; Writing-review and editing, L.S., T.V., S.K., H.G., M.P., S.G., S.E. and D.C.A.; Project administration, V.L.W., A.T., L.S., T.V., S.K. and H.W. All authors have read and agreed to the published version of the manuscript.

Funding: This work was supported by the Research Council of Lithuania (SEN-08/2016), the Swedish Research Council for Sport Science (P2019-060), the Swedish Society for Medical re-search (SSMF, D.C.A.: S16-0159), The Jeansson's foundation (D.C.A.: JS2018-0131), the Swedish Heart-Lung Foundation (D.C.A.: 20180637, 2016074), the Johnson \& Johnson Innovation (S.E.), the Swedish Medical Research Council (S.E.: 2017-00875; H.W.: 2018-02576), the Lars Hierta Foundation (V.L.W.: FO2019-0406), Loo and Hans Osterman Foundation for Medical Research (V.L.W.: FS-2021:0004), and the Estonian Ministry of Education and Science (IUT 20-58).

Institutional Review Board Statement: The study was conducted according to the guidelines of the Decla-ration of Helsinki, and approved by the Kaunas Regional Biomedical Research Ethics Committee (ethics number BE-2-35).

Informed Consent Statement: Informed consent was obtained from all subjects involved in the study. 
Data Availability Statement: Data is contained within the article.

Acknowledgments: Figures 1 and 5 were created with BioRender.com (accessed on 6 July 2021).

Conflicts of Interest: The authors declare that there is no conflict of interest.

\section{References}

1. Chung, H.Y.; Cesari, M.; Anton, S.; Marzetti, E.; Giovannini, S.; Seo, A.Y.; Carter, C.; Yu, B.P.; Leeuwenburgh, C. Molecular inflammation: Underpinnings of aging and age-related diseases. Ageing Res. Rev. 2009, 8, 18-30. [CrossRef]

2. Hunter, S.K.; Pereira, H.M.; Keenan, K.G. The aging neuromuscular system and motor performance. J. Appl. Physiol. 2016, 121, 982-995. [CrossRef] [PubMed]

3. Kim, B.J.; Lee, S.H.; Koh, J.M. Clinical insights into the kynurenine pathway in age-related diseases. Exp. Gerontol. 2020, 130, 110793. [CrossRef] [PubMed]

4. Cervenka, I.; Agudelo, L.Z.; Ruas, J.L. Kynurenines: Tryptophan's metabolites in exercise, inflammation, and mental health. Science 2017, 357, eaaf9794. [CrossRef]

5. Martin, K.S.; Azzolini, M.; Lira Ruas, J. The kynurenine connection: How exercise shifts muscle tryptophan metabolism and affects energy homeostasis, the immune system, and the brain. Am. J. Physiol. Cell Physiol. 2020, 318, C818-C830. [CrossRef] [PubMed]

6. Giil, L.M.; Midttun, O.; Refsum, H.; Ulvik, A.; Advani, R.; Smith, A.D.; Ueland, P.M. Kynurenine pathway metabolites in Alzheimer's disease. J. Alzheimers Dis. 2017, 60, 495-504. [CrossRef]

7. de Bie, J.; Guest, J.; Guillemin, G.J.; Grant, R. Central kynurenine pathway shift with age in women. J. Neurochem. 2016, 136, 995-1003. [CrossRef]

8. Chang, K.H.; Cheng, M.L.; Tang, H.Y.; Huang, C.Y.; Wu, Y.R.; Chen, C.M. Alternations of metabolic profile and kynurenine metabolism in the plasma of Parkinson's disease. Mol. Neurobiol. 2018, 55, 6319-6328. [CrossRef]

9. Theofylaktopoulou, D.; Midttun, O.; Ulvik, A.; Ueland, P.M.; Tell, G.S.; Vollset, S.E.; Nygard, O.; Eussen, S.J. A community-based study on determinants of circulating markers of cellular immune activation and kynurenines: The Hordaland Health Study. Clin. Exp. Immunol. 2013, 173, 121-130. [CrossRef]

10. Sas, K.; Szabo, E.; Vecsei, L. Mitochondria, oxidative stress and the kynurenine system, with a focus on ageing and neuroprotection. Molecules 2018, 23, 191. [CrossRef]

11. Westbrook, R.; Chung, T.; Lovett, J.; Ward, C.; Joca, H.; Yang, H.; Khadeer, M.; Tian, J.; Xue, Q.L.; Le, A.; et al. Kynurenines link chronic inflammation to functional decline and physical frailty. JCI Insight 2020, 5, e136091. [CrossRef]

12. Han, Q.; Cai, T.; Tagle, D.A.; Li, J. Structure, expression, and function of kynurenine aminotransferases in human and rodent brains. Cell Mol. Life Sci. 2010, 67, 353-368. [CrossRef] [PubMed]

13. Kessler, M.; Terramani, T.; Lynch, G.; Baudry, M. A glycine site associated with N-methyl-D-aspartic acid receptors: Characterization and identification of a new class of antagonists. J. Neurochem. 1989, 52, 1319-1328. [CrossRef] [PubMed]

14. Grant, R.S.; Coggan, S.E.; Smythe, G.A. The physiological action of picolinic Acid in the human brain. Int. J. Tryptophan Res. 2009, 2, 71-79. [CrossRef] [PubMed]

15. Erhardt, S.; Schwieler, L.; Imbeault, S.; Engberg, G. The kynurenine pathway in schizophrenia and bipolar disorder. Neuropharmacology 2017, 112, 297-306. [CrossRef]

16. Gulaj, E.; Pawlak, K.; Bien, B.; Pawlak, D. Kynurenine and its metabolites in Alzheimer's disease patients. Adv. Med. Sci. 2010, 55, 204-211. [CrossRef] [PubMed]

17. Sellgren, C.M.; Gracias, J.; Jungholm, O.; Perlis, R.H.; Engberg, G.; Schwieler, L.; Landen, M.; Erhardt, S. Peripheral and central levels of kynurenic acid in bipolar disorder subjects and healthy controls. Transl. Psychiatry 2019, 9, 37. [CrossRef]

18. Guillemin, G.J. Quinolinic acid, the inescapable neurotoxin. FEBS J. 2012, 279, 1356-1365. [CrossRef]

19. Andersson, D.C.; Betzenhauser, M.J.; Reiken, S.; Meli, A.C.; Umanskaya, A.; Xie, W.; Shiomi, T.; Zalk, R.; Lacampagne, A.; Marks, A.R. Ryanodine receptor oxidation causes intracellular calcium leak and muscle weakness in aging. Cell Metab. $2011,14,196-207$. [CrossRef]

20. Savitz, J. The kynurenine pathway: A finger in every pie. Mol. Psychiatry 2020, 25, 131-147. [CrossRef]

21. Joseph, A.M.; Adhihetty, P.J.; Leeuwenburgh, C. Beneficial effects of exercise on age-related mitochondrial dysfunction and oxidative stress in skeletal muscle. J. Physiol. 2016, 594, 5105-5123. [CrossRef] [PubMed]

22. Cheng, A.J.; Yamada, T.; Rassier, D.E.; Andersson, D.C.; Westerblad, H.; Lanner, J.T. Reactive oxygen/nitrogen species and contractile function in skeletal muscle during fatigue and recovery. J. Physiol. 2016, 594, 5149-5160. [CrossRef] [PubMed]

23. Trewin, A.J.; Parker, L.; Shaw, C.S.; Hiam, D.S.; Garnham, A.; Levinger, I.; McConell, G.K.; Stepto, N.K. Acute HIIE elicits similar changes in human skeletal muscle mitochondrial $\mathrm{H}_{2} \mathrm{O}_{2}$ release, respiration, and cell signaling as endurance exercise even with less work. Am. J. Physiol. Regul. Integr. Comp. Physiol. 2018, 315, R1003-R1016. [CrossRef] [PubMed]

24. Morrison, D.; Hughes, J.; Della Gatta, P.A.; Mason, S.; Lamon, S.; Russell, A.P.; Wadley, G.D. Vitamin C and E supplementation prevents some of the cellular adaptations to endurance-training in humans. Free Radic. Biol. Med. 2015, 89, 852-862. [CrossRef] [PubMed] 
25. Paulsen, G.; Cumming, K.T.; Holden, G.; Hallen, J.; Ronnestad, B.R.; Sveen, O.; Skaug, A.; Paur, I.; Bastani, N.E.; Ostgaard, H.N.; et al. Vitamin C and E supplementation hampers cellular adaptation to endurance training in humans: A double-blind, randomised, controlled trial. J. Physiol. 2014, 592, 1887-1901. [CrossRef]

26. Wyckelsma, V.L.; Venckunas, T.; Brazaitis, M.; Gastaldello, S.; Snieckus, A.; Eimantas, N.; Baranauskiene, N.; Subocius, A.; Skurvydas, A.; Paasuke, M.; et al. Vitamin C and E treatment blunts sprint interval training-induced changes in inflammatory mediator-, calcium-, and mitochondria-related signaling in recreationally active elderly humans. Antioxidants (Basel) $2020,9,879$. [CrossRef] [PubMed]

27. Ristow, M.; Zarse, K.; Oberbach, A.; Kloting, N.; Birringer, M.; Kiehntopf, M.; Stumvoll, M.; Kahn, C.R.; Bluher, M. Antioxidants prevent health-promoting effects of physical exercise in humans. Proc. Natl. Acad. Sci. USA 2009, 106, 8665-8670. [CrossRef]

28. Wadley, G.D.; McConell, G.K. High-dose antioxidant vitamin C supplementation does not prevent acute exercise-induced increases in markers of skeletal muscle mitochondrial biogenesis in rats. J. Appl. Physiol. 2010, 108, 1719-1726. [CrossRef]

29. Higashida, K.; Kim, S.H.; Higuchi, M.; Holloszy, J.O.; Han, D.H. Normal adaptations to exercise despite protection against oxidative stress. Am. J. Physiol. Endocrinol. Metab. 2011, 301, E779-E784. [CrossRef] [PubMed]

30. Agudelo, L.Z.; Femenia, T.; Orhan, F.; Porsmyr-Palmertz, M.; Goiny, M.; Martinez-Redondo, V.; Correia, J.C.; Izadi, M.; Bhat, M.; Schuppe-Koistinen, I.; et al. Skeletal muscle PGC-1alpha1 modulates kynurenine metabolism and mediates resilience to stress-induced depression. Cell 2014, 159, 33-45. [CrossRef]

31. Joisten, N.; Kummerhoff, F.; Koliamitra, C.; Schenk, A.; Walzik, D.; Hardt, L.; Knoop, A.; Thevis, M.; Kiesl, D.; Metcalfe, A.J.; et al Exercise and the kynurenine pathway: Current state of knowledge and results from a randomized cross-over study comparing acute effects of endurance and resistance training. Exerc. Immunol. Rev. 2020, 26, 24-42. [PubMed]

32. Schlittler, M.; Goiny, M.; Agudelo, L.Z.; Venckunas, T.; Brazaitis, M.; Skurvydas, A.; Kamandulis, S.; Ruas, J.L.; Erhardt, S.; Westerblad, H.; et al. Endurance exercise increases skeletal muscle kynurenine aminotransferases and plasma kynurenic acid in humans. Am. J. Physiol. Cell Physiol. 2016, 310, C836-C840. [CrossRef] [PubMed]

33. Allison, D.J.; Nederveen, J.P.; Snijders, T.; Bell, K.E.; Kumbhare, D.; Phillips, S.M.; Parise, G.; Heisz, J.J. Exercise training impacts skeletal muscle gene expression related to the kynurenine pathway. Am. J. Physiol. Cell Physiol. 2019, 316, C444-C448. [CrossRef] [PubMed]

34. Millischer, V.; Erhardt, S.; Ekblom, O.; Forsell, Y.; Lavebratt, C. Twelve-week physical exercise does not have a long-lasting effect on kynurenines in plasma of depressed patients. Neuropsychiatr. Dis. Treat. 2017, 13, 967-972. [CrossRef] [PubMed]

35. Place, N.; Ivarsson, N.; Venckunas, T.; Neyroud, D.; Brazaitis, M.; Cheng, A.J.; Ochala, J.; Kamandulis, S.; Girard, S.; Volungevicius, G.; et al. Ryanodine receptor fragmentation and sarcoplasmic reticulum $\mathrm{Ca}^{2+}$ leak after one session of high-intensity interval exercise. Proc. Natl. Acad. Sci. USA 2015, 112, 15492-15497. [CrossRef]

36. Trepci, A.; Imbeault, S.; Wyckelsma, V.L.; Westerblad, H.; Hermansson, S.; Andersson, D.C.; Piehl, F.; Venckunas, T.; Brazaitis, M.; Kamandulis, S.; et al. Quantification of plasma kynurenine metabolites following one bout of sprint interval exercise. Int. J. Tryptophan Res. 2020, 13, 1178646920978241. [CrossRef]

37. Isung, J.; Granqvist, M.; Trepci, A.; Huang, J.; Schwieler, L.; Kierkegaard, M.; Erhardt, S.; Jokinen, J.; Piehl, F. Differential effects on blood and cerebrospinal fluid immune protein markers and kynurenine pathway metabolites from aerobic physical exercise in healthy subjects. Sci. Rep. 2021, 11, 1669. [CrossRef]

38. Magistris, M.R.; Kohler, A.; Pizzolato, G.; Morris, M.A.; Baroffio, A.; Bernheim, L.; Bader, C.R. Needle muscle biopsy in the investigation of neuromuscular disorders. Muscle Nerve 1998, 21, 194-200. [CrossRef]

39. Badawy, A.A.; Guillemin, G. The plasma [knurenine]/[tryptophan] ratio and indoleamine 2,3-dioxygenase: Time for appraisal. Int. J. Tryptophan Res. 2019, 12, 1178646919868978. [CrossRef]

40. Savitz, J.; Drevets, W.C.; Wurfel, B.E.; Ford, B.N.; Bellgowan, P.S.; Victor, T.A.; Bodurka, J.; Teague, T.K.; Dantzer, R. Reduction of kynurenic acid to quinolinic acid ratio in both the depressed and remitted phases of major depressive disorder. Brain Behav. Immun. 2015, 46, 55-59. [CrossRef]

41. Myint, A.M.; Kim, Y.K.; Verkerk, R.; Scharpe, S.; Steinbusch, H.; Leonard, B. Kynurenine pathway in major depression: Evidence of impaired neuroprotection. J. Affect. Disord. 2007, 98, 143-151. [CrossRef]

42. Busse, M.; Busse, S.; Myint, A.M.; Gos, T.; Dobrowolny, H.; Muller, U.J.; Bogerts, B.; Bernstein, H.G.; Steiner, J. Decreased quinolinic acid in the hippocampus of depressive patients: Evidence for local anti-inflammatory and neuroprotective responses? Eur. Arch. Psychiatry Clin. Neurosci. 2015, 265, 321-329. [CrossRef] [PubMed]

43. Heyes, M.P.; Saito, K.; Crowley, J.S.; Davis, L.E.; Demitrack, M.A.; Der, M.; Dilling, L.A.; Elia, J.; Kruesi, M.J.; Lackner, A.; et al. Quinolinic acid and kynurenine pathway metabolism in inflammatory and non-inflammatory neurological disease. Brain 1992, 115, 1249-1273. [CrossRef] [PubMed]

44. Lapin, I.P. Neurokynurenines (NEKY) as common neurochemical links of stress and anxiety. Adv. Exp. Med. Biol. 2003, 527, 121-125. [CrossRef] [PubMed]

45. Gleeson, M.; Bishop, N.C.; Stensel, D.J.; Lindley, M.R.; Mastana, S.S.; Nimmo, M.A. The anti-inflammatory effects of exercise: Mechanisms and implications for the prevention and treatment of disease. Nature Rev. Immunol. 2011, 11, 607-615. [CrossRef] [PubMed]

46. Bhat, A.; Pires, A.S.; Tan, V.; Babu Chidambaram, S.; Guillemin, G.J. Effects of sleep deprivation on the tryptophan metabolism. Int. J. Tryptophan Res. 2020, 13, 1178646920970902. [CrossRef] 
47. Baratta, A.M.; Buck, S.A.; Buchla, A.D.; Fabian, C.B.; Chen, S.; Mong, J.A.; Pocivavsek, A. Sex differences in hippocampal memory and kynurenic acid formation following acute sleep deprivation in rats. Sci. Rep. 2018, 8, 6963. [CrossRef] [PubMed]

48. Mason, S.A.; Trewin, A.J.; Parker, L.; Wadley, G.D. Antioxidant supplements and endurance exercise: Current evidence and mechanistic insights. Redox Biol. 2020, 35, 101471. [CrossRef] [PubMed]

49. Kubicova, L.; Hadacek, F.; Chobot, V. Quinolinic acid: Neurotoxin or oxidative stress modulator? Int. J. Mol. Sci. 2013, 14, 21328-21338. [CrossRef] [PubMed]

50. Radak, Z.; Ishihara, K.; Tekus, E.; Varga, C.; Posa, A.; Balogh, L.; Boldogh, I.; Koltai, E. Exercise, oxidants, and antioxidants change the shape of the bell-shaped hormesis curve. Redox Biol. 2017, 12, 285-290. [CrossRef] [PubMed]

51. Gibala, M.J.; Little, J.P.; Macdonald, M.J.; Hawley, J.A. Physiological adaptations to low-volume, high-intensity interval training in health and disease. J. Physiol. 2012, 590, 1077-1084. [CrossRef] [PubMed]

52. Weston, M.; Taylor, K.L.; Batterham, A.M.; Hopkins, W.G. Effects of low-volume high-intensity interval training (HIT) on fitness in adults: A meta-analysis of controlled and non-controlled trials. Sports Med. 2014, 44, 1005-1017. [CrossRef]

53. Gist, N.H.; Fedewa, M.V.; Dishman, R.K.; Cureton, K.J. Sprint interval training effects on aerobic capacity: A systematic review and meta-analysis. Sports Med. 2014, 44, 269-279. [CrossRef]

54. Sloth, M.; Sloth, D.; Overgaard, K.; Dalgas, U. Effects of sprint interval training on $\mathrm{VO}_{2 \max }$ and aerobic exercise performance: A systematic review and meta-analysis. Scand. J. Med. Sci. Sports 2013, 23, e341-e352. [CrossRef] [PubMed]

55. Knowles, A.M.; Herbert, P.; Easton, C.; Sculthorpe, N.; Grace, F.M. Impact of low-volume, high-intensity interval training on maximal aerobic capacity, health-related quality of life and motivation to exercise in ageing men. Age 2015, 37, 25. [CrossRef] [PubMed] 